\title{
O uso do poder militar dos Estados Unidos contra o Estado Islâmico do Iraque e do Levante
}

\author{
The use of military power of the United States \\ against the Islamic State of Iraq and the Levant
}

Cláudio Júnior Damin*

\section{Resumo}

O artigo analisa a decisão do presidente Barack Obama de mobilizar as forças armadas norte-americanas para combater o Islâmico do Iraque e do Levante (EIIL) nas regiões controladas pelo grupo no Oriente Médio. Busca-se encontrar as bases legais e institucionais para essas ações militares e mapear duas fases de respostas do presidente norte-americano contra o EIIL. O artigo mostra que a administração de Barack Obama baseia a legitimidade dos ataques aéreos contra o grupo como uma prerrogativa do presidente enquanto comandante-em-chefe, além de interpretar essas ações militares como um prolongamento da guerra contra o terrorismo iniciada em 2001.

Palavras-chave: Política Internacional; Segurança internacional; Estados Unidos; Terrorismo; Estado Islâmico

\section{Abstract}

The article analyzes the decision of President Barack Obama to mobilized US military to combat the Islamic State of Iraq and the Levant (ISIL) in the regions controlled by the group in the Middle East. The purpose is finding the legal and institutional bases for these military actions and map two phases of responses from Obama against EIIL. The article points that the Obama administration has based the legitimacy of air strikes against the group as a prerogative of the president as commander-in-chief, as well interpret these military actions as an extension of the war on terrorism began in 2001.

Keywords: International Policy; International Security; United States; Terrorism; Islamic State

\footnotetext{
* Doutor em Ciência Política (UFRGS). Professor na Universidade Federal do Pampa (UNIPAMPA), campus São Borja (RS). E-mail: superdamin@terra.com.br
} 


\section{Introdução}

A presidência de Barack Obama, desde agosto de 2014, empreende oficialmente no território iraquiano e sírio operações militares aéreas contra militantes do chamado Estado Islâmico do Iraque e do Levante (EIIL). O grupo islâmico sunita jihadista proclamou, em 2013, a criação de um "Estado" que abarca desde o norte da Síria até a porção oeste do Iraque.

Esse grupo fundamentalista, a exemplo do que fez a Al-Qaeda em 1996 e 1998 (HOFFMAN, 2014), declarou guerra contra os Estados Unidos em 2014, em seu caso a partir de um vídeo publicado na internet (ISIS VIDEO, 2014). Passados treze anos desde os atentados terroristas de 11 de Setembro promovidos pela Al-Qaeda de Osama bin Laden, a "guerra contra o terrorismo" parece novamente retornar, com ênfase, à cena pública norte-americana.

Dentro desse contexto, o artigo busca responder à seguinte pergunta de pesquisa: quais as ações de Washington contra o EIIL e quais suas bases legitimadoras legais e institucionais? O principal objetivo do artigo é o de avaliar a decisão do presidente Barack Obama de mobilizar as forças armadas norte-americanas para destruir a infraestrutura e eliminar os membros do EIIL nas regiões controladas por esse grupo.

A hipótese do artigo assevera que a resposta da administração Obama ao EllL é formada por duas fases distintas, com variadas bases legitimadoras. Na primeira delas, que se estende desde agosto de 2014 até o momento, o presidente interpreta as ações contra o Estado Islâmico como um prolongamento da guerra contra o terrorismo iniciada em 2001, sendo seu documento legitimador a Autorização para o Uso da Força Militar (AUFM) assinada por seu antecessor e validada pelo Congresso norte-americano ainda em setembro de 2001. Nessa fase, vale destacar, há uma interdição para combates com tropas terrestres no Iraque e na Síria, limitando o esforço militar à utilização do poder aéreo norte-americano.

A segunda fase é inaugurada pela solicitação de Obama para que o Congresso aprove uma autorização para que as forças armadas sejam utilizadas por um período de três anos na Síria e no Iraque contra "pessoas e forças associadas" ao grupo terrorista. Nessa fase uma inflexão importante é operada, uma vez que há previsão de que tropas terrestres sejam enviadas à área conflagrada, permitindo combates terrestres, mesmo que a partir de uma visão flexibilizada da atuação em solo dos soldados dos Estados Unidos. Essa segunda fase, no entanto, até o momento (outubro de 2015) não se efetivou em função da não apreciação, por parte dos congressistas, de autorização específica para um maior engajamento de Washington.

Para cumprir o objetivo do artigo, bem como mapear as duas distintas fases de resposta e suas bases legitimadoras, será utilizada a metodologia qualitativa com o exame e a análise de documentos legais dos Estados Unidos, com especial atenção à AUFM contra a Al-Qaeda e seus associados em 2001, e pronunciamentos de membros da administração democrata de Barack Obama. A partir desse material teremos elementos para analisar a resposta militar do governo norte-americano contra o ElIL.

O presente artigo se justifica em função da atualidade do tema e da escassez de pesquisas acadêmicas no Brasil sobre as recentes iniciativas militares norte-americanas contra o chamado Estado Islâmico. Os Estados Unidos estão particularmente envolvidos nas contramedidas que objetivam conter o avanço e a institucionalização desta organização terrorista e insurgente no 
Oriente Médio, razão pela qual se faz necessário uma apropriação desse conhecimento acerca da dinâmica e das possibilidades dessas ações militares. O ElIL tem cada vez mais se tornado uma ameaça para um conjunto de Estados e regiões do sistema internacional, despertando um consequente interesse na comunidade epistemológica de ciência política e relações internacionais. Nossa investigação, portanto, se perfila a esse esforço de compreensão desta "nova ameaça" ao sistema internacional.

Além desta Introdução, o artigo está dividido em três partes básicas. Na primeira delas analisamos a primeira fase do combate ao EIIL, a partir basicamente da utilização do poder aéreo, relevando a importância da AUFM de 2001 para o prosseguimento da "guerra ao terror" pela administração de Barack Obama. Na parte seguinte enfocamos uma segunda fase do esforço contra o grupo terrorista analisando o pedido de uma AUFM específica para combater e destruir o EIIL, abrindo a possibilidade do envio de tropas terrestres à região em beligerância. Na parte final do artigo tecemos algumas considerações sobre as questões tratadas ao longo do texto e perspectivas sobre o impasse que atualmente se estabelece entre Executivo e Legislativo para iniciar uma segunda fase do combate contra o ElIL.

\section{Fase I: poder aéreo e a AUFM de 2001}

Tem sido comum, desde que a televisão se tornou um veículo de comunicação de massa nos Estados Unidos, que os presidentes utilizem-na para pronunciar-se aos cidadãos particularmente sobre temas ligados à segurança nacional (KERNELL, 2006; RAMSEY, 2003). No caso de Barack Obama, o presidente foi à televisão para, por exemplo, informar a morte de Osama bin Laden e o início da campanha aérea contra a Líbia do então ditador Muammar Gaddafi, ambos acontecimentos do ano de 2011.

Já o primeiro discurso público de Barack Obama que tratou exclusivamente do combate ao EIIL ocorreu no dia 10 de setembro de 2014. Poderíamos mesmo assinalar essa data como marco da transformação do EIIL em um reconhecido problema de segurança nacional para os Estados Unidos, um "problema público" que mereceria, por sua vez, políticas públicas de segurança pertinentes. Nesse pronunciamento aos cidadãos norte-americanos, o presidente revelava 0 que ele, juntamente com "amigos e aliados", faria "para desintegrar e, finalmente, destruir o grupo terrorista conhecido como EIIL" (OBAMA, 2014, p. 1, tradução nossa).

O EIIL é retratado pelo presidente como uma das "grandes ameaças" originadas no Oriente Médio, o que faz com que, mesmo passados mais de treze anos desde o 11 de Setembro, "ainda continuamos a enfrentar uma ameaça terrorista" (OBAMA, 2014, p. 1, tradução nossa). Na definição presidencial, o EIIL seria um antigo afiliado da Al-Qaeda no Iraque que, desgarrado da organização de bin Laden, conquistou poder e influência a partir da guerra civil na Síria e avançou territorialmente na fronteira daquele país com o Iraque. Obama nega as pretensões estatais do grupo - "ElIL certamente não é um Estado" -, conceituando-o como "uma organização terrorista, pura e simples" (OBAMA, 2014, p. 1, tradução nossa).

O problema, reconhecido por Obama (2014, p. 1, tradução nossa), é que "nós não podemos apagar todos os vestígios do mal do mundo, e pequenos grupos de assassinos possuem a 
capacidade de produzir grandes danos", sendo o ElIL uma dessas organizações capazes de ameaçar o sistema internacional, particularmente a partir de sua estratégia sectária de atuação e práticas brutais contra aqueles que o grupo considera seus inimigos.

A existência do EIIL é percebida como uma ameaça para os cidadãos da Síria, do Iraque, para o Oriente Médio como um todo e para os Estados Unidos, seus cidadãos e instalações na região. Adicionalmente, Obama informa à nação que, segundo informado pela comunidade de inteligência, milhares de estrangeiros (europeus e norte-americanos) têm aderido às fileiras do EIIL na Síria e no Iraque, o que potencializa a ameaça para os países do Ocidente, uma vez que "esses combatentes poderiam tentar regressar aos seus países de origem e realizar ataques mortais" (OBAMA, 2014, p. 1, tradução nossa).

É, pois, a partir dessa ameaça que paira sobre a segurança da nação, e de seus interesses no nivel internacional, que Obama informa a seus compatriotas ações para debelar esse novo inimigo que acossa a população dos Estados Unidos. Antes, porém, de informar o que tem feito e o que será feito contra o EIIL, Obama declara que, "como comandante-em-chefe, minha mais alta prioridade é a segurança do povo americano" (OBAMA, 2014, p. 1, tradução nossa). Aqui o democrata invoca seu poder de comando sobre as forças armadas do país e sua prerrogativa de garantir a integridade da população e do território norte-americano. Ao aludir a esse poder, Obama está sinalizando que sua ação contra o ElIL encontra amparo em seu poder enquanto comandante-em-chefe do país, não necessitando de uma autorização do Congresso para agir em termos militares.

Essa interpretação de que há um poder inerente do presidente enquanto comandante-em-chefe', não sendo, portanto, subordinado ao Congresso, conforme estabelece a chamada Cláusula da Guerra² da Constituição, é explícita no pronunciamento do democrata. Uma evidência é a seguinte informação que Obama fornece ao grande público assistindo a seu pronunciamento através da televisão:

No mês passado eu ordenei nossos militares a tomar medidas direcionadas contra o EllL para interromper seus avanços. Desde então, realizamos com sucesso mais de 150 ataques aéreos no Iraque. Esses ataques protegeram o pessoal americano e instalações, mataram combatentes do ElIL, destruíram armas e forneceram espaço para que as forças iraquianas e curdas recuperem territórios chaves. (OBAMA, 2014, p. 2, tradução nossa)

Há algumas questões a serem assinaladas nessa passagem. Uma primeira, de grande repercussão sobre a interpretação do presidente a respeito de seus poderes de guerra, é a de que, evacuado de qualquer autorização congressual específica, o poder aéreo norte-americano desde agosto de 2014 tem sido utilizado contra o ElIL no Iraque. Trata-se de ataques limitados e

1 A chamada Cláusula do Comandante-em-Chefe está presente na seção II do artigo $2^{\circ}$ da Constituição e de define que: "O presidente será o comandante-em-chefe do exército e da marinha dos Estados Unidos, e da milícia dos diversos estados quando chamada em serviço para os Estados Unidos" (ELLIOT, 1836, Vol. I, p. 11, tradução nossa). Particularmente a partir da Guerra da Coreia na década de 1950, esta Cláusula começa a ser interpretada como um poder totalmente desligado da Cláusula da Guerra, conferindo poderes unilaterais de guerra ao presidente (DAMIN, 2013).

2 A Cláusula da Guerra é encontrada na seção VIII da Constituição e trata das competências do Legislativo. É do Congresso, assinala o texto, o poder de "declarar guerra, emitir cartas de corso e de represália e fazer regras relativas às capturas em terra e mar" (ELLIOT, 1836, Vol. I, p. 6, tradução nossa). 
sem a presença de tropas terrestres, a mesma estratégia adotada pela administração democrata em seu envolvimento no conflito líbio em 2011 (DAMIN, 2012). Uma segunda questão importante é o fato de Obama ter dito que "eu ordenei" as ações militares contra a organização terrorista. Aqui Obama assume para si o poder de utilizar as forças armadas sem qualquer autorização legislativa prévia.

Dentre as principais medidas que seriam tomadas dali em diante e que integrariam uma estratégia de contraterrorismo consta, em primeiro lugar, o prosseguimento de uma "campanha sistemática de ataques aéreos contra esses terroristas" (OBAMA, 2014, p. 2, tradução nossa). Tal esforço seria realizado em conjunto com as forças militares iraquianas. Obama destaca, ainda, que ele já deixara claro que os Estados Unidos irão caçar terroristas que ameaçam o país "onde quer que estejam", o que significa, em suas palavras, que "eu não hesitarei em tomar medidas contra o EIIL na Síria, assim como no Iraque" (OBAMA, 2014, p. 2, tradução nossa).

Em segundo lugar, Obama promete aumentar o apoio às tropas terrestres que combatem os membros do ElIL, destacando que em junho de 2014 já havia enviado centenas de militares para ajudar no treinamento das forças de segurança iraquianas. Esse aumento, em termos quantitativos, representaria mais 475 militares para o Iraque. Obama (2014, p. 2, tradução nossa) esclarece, no entanto, que "essas forças americanas não terão missão de combate", sendo necessárias para apoiar os contingentes regulares iraquianos e as forças curdas "com treinamento, inteligência e equipamento".

O presidente aqui quer afastar-se de uma percepção que poderia surgir na opinião pública norte-americana de que, ao enviar oficiais militares, ele colocaria novamente o país envolto em um conflito armado de grandes dimensões, tal qual o do Iraque a partir de 2003. 0 esforço militar contra o EIIL seria distinto da participação norte-americana no Iraque e Afeganistão, pois basicamente "ele não vai envolver tropas de combate americanas lutando em solo estrangeiro" (OBAMA, 2014, p. 2, tradução nossa). Apenas o poder aéreo do país, e que envolve menores riscos aos soldados norte-americanos, seria utilizado e sempre em comunhão com uma coalizão de parceiros.

Em nenhum momento do pronunciamento Obama faz referência a um pedido de autorização congressual para agir contra o ElIL. O presidente simplesmente informa que sua administração assegurou, a partir de consultas com líderes partidários no Legislativo, o apoio bipartidário às medidas que estava comunicando à população norte-americana naquela noite. O Congresso, segundo sua visão, deveria apoiá-lo no esforço contra o ElIL. Na acepção de Obama (2014, p. 2, tradução nossa), é o presidente quem detém a autoridade para combater os extremistas, devendo o Congresso seguir seu presidente a fim de demonstrar a unidade dos ramos do governo contra o inimigo. "Eu tenho a autoridade para enfrentar a ameaça do EIIL, mas eu acredito que nós somos mais fortes como nação quando o presidente e o Congresso trabalham juntos", vaticinou. Não é mencionada autorização, mas sim apoio.

No final da tarde do dia 10 de setembro, poucas horas antes do pronunciamento de Barack Obama aos cidadãos norte-americanos, a Casa Branca providenciou uma conferência, via telefone, com alguns jornalistas e altos funcionários do governo democrata a fim de discutir o discurso que o presidente iria proferir à noite. A transcrição disponível desta conferência é importante porque, em primeiro lugar, significa o posicionamento oficial do Executivo em relação 
à legitimidade da ação militar contra o ElIL e, por segundo, é complementar aos argumentos exarados por Obama na televisão.

Um jornalista questionou se não seria necessária uma autorização do Congresso para que o presidente pudesse dar prosseguimento à sua estratégia de contraterrorismo em relação ao EIIL. Um funcionário do governo, que não é identificado nominalmente, declarou que "o presidente tem autoridade constitucional e legal para estabelecer operações de ataque aéreo militar dos EUA para lidar com a ameaça representada pelo EIIL" (BACKGROUND CONFERENCE, 2014, p. 4-5, tradução nossa).

A autoridade "constitucional" se refere à seção II do artigo segundo da Constituição que destina ao chefe do Executivo o comando das forças armadas do país. Nas últimas décadas, essa chamada Cláusula do Comandante-em-Chefe tem sido utilizada por todos os presidentes para agir militarmente no exterior alegando não necessitar de qualquer autorização do Legislativo (DAMIN, 2013).

No caso da autoridade "legal", o representante do governo insere um novo argumento, conforme indica:

Mas, para ser claro, nós não acreditamos que o presidente precisa de uma nova autorização a fim de tomar uma ação sustentada contra EIIL. Nós acreditamos que ele pode invocar a AUFM de 2001 como autoridade legal para as operações militares aéreas que ele está direcionando contra EIIL, por exemplo. (BACKGROUND CONFERENCE, 2014, p. 5, tradução nossa)

O argumento central aqui é o de que a Autorização para o Uso da Força Militar de 2001 seria igualmente válida para o combate do grupo Estado Islâmico. Esse argumento também surgiu no dia seguinte ao pronunciamento televisivo do presidente quando, na coletiva de imprensa, o porta-voz do governo, John Earnest, foi questionado sobre a base legal que legitimaria as ações anunciadas por Obama. Ele se referiu à autoridade constitucional presidencial para autorizar as ordens militares da noite seguinte e também citou a AUFM. Segundo o porta-voz, o presidente "acredita" que a AUFM de 2001 "continua a aplicar-se a essa organização terrorista [o EIIL] que está operando no Iraque e na Síria” (EARNEST, 2014, p. 1, tradução nossa).

Por fim, esse mesmo argumento da AUFM como fonte legitimadora para as ações militares de Obama contra o ElIL é encontrado em um e-mail enviado a um jornalista do The New York Times e assinado por um alto funcionário da administração democrata. Segundo explicou esse burocrata, o presidente estaria autorizado a empreender a força militar porque sustentado em um documento legal, a AUFM, e também, de forma alternativa, na autorização para o uso da Força Militar contra o Iraque de 2002 (TSANG, 2014). Obama, nesse sentido, teria a seu favor leis previamente aprovadas pelo Congresso.

É importante, nesse ponto, que tratemos de modo mais específico sobre o espírito e o conteúdo da AUFM de 2001, vista pela administração de Obama como uma das fontes legitimadoras para a ação do presidente contra o EIIL e argumento central da primeira fase da campanha. Para melhor compreendermos essa primeira fase da luta contra esse grupo terrorista é necessário, portanto, conferir significado a essa legislação produzida nos primeiros momentos após o 11 de Setembro de 2001. 
Podemos afirmar que o principal instrumento legal que permitiu o início da denominada "guerra contra o terrorismo" foi a AUFM aprovada pelo Congresso dos Estados Unidos no dia 18 de setembro de 2001. Trata-se, sem exagero, do documento fundante da "guerra contra o terror" iniciada por W. Bush e, agora, continuada por Obama.

Essa autorização fora aprovada, sem qualquer oposição mais significativa, pela Câmara dos Representantes e pelo Senado em um clima de consternação nacional ensejado pelos ataques terroristas em solo norte-americano. 0 texto dimensiona o contexto em que estava sendo aprovada, a saber:

- Os atentados de 11 de Setembro de 2001 são classificados como "atos de violência traiçoeira contra os Estados Unidos e seus cidadãos" (AUMF, 2001, p. 224, tradução nossa);

- Eles permitem, devido à sua natureza, que o país exercite seu direito à legítima defesa para proteger os cidadãos norte-americanos interna e externamente;

- Mesmo findos em sua execução no dia 11 de setembro, os atentados são avaliados como ainda se constituindo em uma "incomum e extraordinária ameaça à segurança internacional e política externa dos Estados Unidos" (AUMF, 2001, p. 224, tradução nossa).

Segundo a AUFM, toda essa situação, particularmente emergencial devido à existência de uma ameaça existencial aos Estados Unidos, seu território, governo e população, requeria a ação do presidente, uma vez que ele, segundo ainda as disposições preliminares da lei, "tem autoridade garantida pela Constituição para agir no sentido de deter e prevenir atos de terrorismo internacional contra os Estados Unidos" (AUMF, 2001, p. 224, tradução nossa).

Essa lei, portanto, possuía um objetivo extremamente claro, permitindo "o uso das Forças Armadas dos Estados Unidos contra os responsáveis pelos recentes ataques perpetrados contra os Estados Unidos" (AUMF, 2001, tradução nossa). Era, ao mesmo tempo, demasiadamente ampla no que concerne à destinação desses poderes ao presidente para contornar a emergência nacional decretada em função dos ataques da Al-Qaeda.

O núcleo da AUFM é a alínea "a" do ponto $1^{\circ}$, em que o Congresso deliberou que:

O presidente está autorizado a usar toda a necessária e apropriada força contra aquelas nações, organizações ou pessoas que ele determine tenham planejado, autorizado, cometido ou auxiliado os ataques terroristas que ocorreram em 11 de setembro de 2001, ou que abrigaram tais organizações ou pessoas, com o objetivo de prevenir qualquer futuro ato do terrorismo internacional contra os Estados Unidos por parte dessas nações, organizações ou pessoas. (AUMF, 2001, p. 224, tradução nossa)

Há alguns elementos importantes nessa passagem. Em primeiro lugar, a autorização é circunscrita a um evento irradiador - os atentados terroristas de 2001 -, buscando seus responsáveis. Em segundo lugar, há um sentido de prevenção em relação a eventos futuros, daí necessitando a pronta ação militar do presidente. Um terceiro elemento é o poder soberano destinado ao presidente quando consta que ele determinará os envolvidos nos ataques terroristas. Em quarto lugar, a autorização para agir se refere a três alvos de complexidade 
distinta: Estados, organizações ou pessoas consideradas individualmente. Trata-se, pois, de uma autorização não apenas para iniciar um conflito militar internacional (contra um país, como no caso da intervenção no Afeganistão em outubro de 2001), permitindo também ações militares contra atores não estatais, grupos ou indivíduos que ameacem a segurança nacional. Por fim, não há uma cláusula de caducidade, tal qual outra legislação emergencial (Patriot Act), de tal sorte que a AUFM é legislação sem horizonte temporal estabelecido para expirar.

Há, pois, uma espécie de "pecado original" nessa autorização ilustrado por seu alto grau de generalidade e flexibilidade em relação ao uso da força militar contra os autores do 11 de Setembro e seus associados. Na sentença muito apropriada de Tribe (2004), os congressistas forneceram um "virtual cheque em branco" ao presidente na sua guerra contra o terrorismo. Daí porque, em boa medida, estar sendo utilizado na administração de Obama.

Aliado a isso, vale destacar que a interpretação dada pelo presidente George W. Bush à AUFM foi extremamente ampla, a saber: uma declaração praticamente ilimitada de guerra contra a Al-Qaeda e outras organizações terroristas. A 20 de setembro, dois dias após a aprovação da AUFM, discursando no Capitólio, o presidente Bush demarcou, lastreado pelos poderes a ele conferidos pelo Congresso, uma inédita "declaração de guerra". "Nossa guerra ao terror começa com a Al-Qaeda, mas não termina nela. Não terminará até que todos os grupos terroristas de alcance global sejam encontrados, detidos e derrotados", disse George W. Bush (2001, p. 2, tradução nossa).

A guerra contra o terrorismo, portanto, nessa interpretação dada pelo presidente repuplicano, seria a utilização de todos os meios necessários para desarticular os responsáveis pelo 11 de Setembro e seus aliados. Esse alcance da Autorização foi reconhecido por um memorando de julho de 2013, confeccionado pelo serviço de pesquisa do Congresso norte-americano. 0 texto, assinado pelo analista de leis internacionais Matthew Weed (2013, p. 1, tradução nossa), em relação ao escopo da AUFM esclarece que, mesmo ampla, a autorização "está circunscrita a autorizar apenas o direcionamento àquelas nações, organizações ou pessoas envolvidas nos ataques de 11 de setembro ou àqueles que abrigam os que perpetraram os ataques".

Em termos práticos, de 2001 até o primeiro semestre de 2013 a AUFM foi invocada 30 vezes pela presidência dos Estados Unidos "para tomar ou continuar uma ação militar ou relacionada a ela", incluindo "ações não militares, tais como detenções e julgamentos marciais" (WEED, 2013, p. 2, tradução nossa). Do total dessas três dezenas de ocorrências, dezoito se deram durante a administração de W. Bush e uma dúzia na de Obama. Trata-se, aqui, de uma evidência de que a "guerra contra o terrorismo", mesmo que tenha desaparecido da linguagem oficial utilizada pela administração democrata, ainda persiste em seus fundamentos. Isso porque seu documento primacial, a AUFM, segue válida mesmo após à desarticulação da Al-Q̣aeda no Afeganistão, à morte de seu líder no Paquistão e à prisão e morte de suas principais lideranças em vários países do Oriente Médio.

A relação entre AUFM, AI-Qaeda e EIIL foi exposta pelo alto oficial do governo Obama em correspondência eletrônica com jornalista do The New York Times já referida anteriormente. Segundo esclareceu: 
A AUFM de 2001 autoriza o uso de "toda a necessária e apropriada força contra aquelas nações, organizações ou pessoas" responsáveis pelo 11/09 e aqueles que "abrigaram essas organizações ou pessoas". A Administração [Obama] tem interpretado a AUFM de 2001 para autorizar o uso da força contra a Al-Qaeda, o Talibã e forças associadas. Com base na relação de longa data do EIIL com a Al-Qaeda e Osama bin Laden; sua longa história de realização, e o desejo continuado de realização de ataques contra cidadãos norte-americanos e interesses do país, a extensa história das operações de combate dos EUA contra o ElIL datam do tempo em que o grupo era um afiliado da Al-Qaeda em 2004; e a posição do ElIL - apoiado por alguns membros individuais e facções de grupos alinhados à Al-Qaeda - que é o verdadeiro herdeiro do legado de Osama bin Laden, o presidente poderá invocar a AUFM de 2001 como autoridade legal para o uso da força contra o EIIL, não obstante a divisão pública recente entre a liderança sênior da AI-Qaeda e o EIIL. (TSANG, 2014, p. 1, tradução nossa)

O ElIL, interpretado como uma força associada à Al-Qaeda, na verdade um herdeiro ou sucessor, acabaria coberto pelas disposições da AUFM de 2001. Aqui pode ser observada a amplitude da interpretação dada pelas administrações pós-11 de Setembro ao texto da Autorização. É perceptível, nesse ponto, que a guerra contra o terrorismo, fundada a partir da aprovação da AUFM pelo Congresso, teve seu prosseguimento na gestão de Obama e repercute no atual esforço militar para destruir o EIIL.

A exposição dessa relação entre Al-Qaeda e ElIL também fora feita pelo porta-voz da presidência na coletiva de imprensa do dia seguinte ao pronunciamento televisivo de Obama. John Earnest embasa a aplicabilidade da AUFM de 2001 ao EIIL a partir de quatro razões, a saber:

1. A primeira razão é de natureza histórica. O auxiliar de Obama relembra que há uma década o ElIL se chamava Al-Qaeda no Iraque (AQI), havendo ligações entre "os líderes da Al-Qaeda no Iraque e a liderança da Al-Qaeda, incluindo Osama bin Laden" (EARNEST, 2014, p. 9, tradução nossa);

2. Em segundo lugar, Earnest defende que, mesmo após a "divergência pública" entre a Al-Qaeda e o EIIL datada de fevereiro de 2014, "existem alguns agentes da AlQaeda que indicaram que eles realmente acreditam que o EIIL é o verdadeiro herdeiro de Osama bin Laden" (EARNEST, 2014, p. 10, tradução nossa). Isso seria, na visão da administração democrata, evidência de que os vínculos entre Al-Qaeda e EIIL persistem mesmo após o emir do grupo ter desvinculado completamente a organização do Estado Islâmico;

3. A seguir, o porta-voz salienta que as "táticas brutais" levadas a cabo pelo ISIS seriam as mesmas que eram empregadas quando o grupo ainda se chamava Al-Qaeda no Iraque. A partir dessa evidência, Earnest (2014, p. 10, tradução nossa) conclui que "as táticas da Al-Qaeda no Iraque não mudaram simplesmente porque ela alterou seu nome";

4. Uma quarta e última razão é a semelhança em relação aos objetivos das duas organizações. O governo aqui assinala que o objetivo último da Al-Qaeda "sempre foi a formação de um califado islâmico", uma "ambição" que é compartilhada pelas lideranças do EIIL, de tal modo que os grupos podem ser igualados (EARNEST, 2014, p. 10, tradução nossa). 
Note-se, portanto, que o esforço do governo é o de estabelecer uma linha de continuidade entre a Al-Qaeda e o EIIL. Isso porque apenas assim a AUFM de 2001 seria aplicável ao Estado Islâmico. Trata-se, em boa medida, de uma interpretação elástica do texto da Autorização, porém efetiva para que o presidente possa utilizar o poder aéreo norte-americano contra o grupo jihadista.

Esses quatro argumentos não devem ser tão facilmente absorvidos, uma vez que existem argumentos contrários a esse entendimento sobre a validade da AUFM de 2001. 0 ponto principal é o de que parece ser extremamente problemático estabelecer uma ligação entre os extremistas do Estado Islâmico e os atentados terroristas de 2001 nos Estados Unidos. Dentre outras razões, porque o que hoje conhecemos com ElIL passou por transformações que alteraram, por exemplo, sua denominação, lideranças e estrutura organizacional.

O grupo, em seus primórdios, surgiu com o jordaniano Abu Musab al-Zarqawi que, em 1999, mudou-se para o Afeganistão dos talibãs e, autorizado por Osama bin Laden, estabeleceu um campo de treinamento de extremistas naquele país. Zarqawi fundou o Jund al-Sham que, transcorridos alguns meses, passou a se chamar Jama Jama`at al-Tawhid wa al-jihad (JTWJ) e, ainda em 1999, cometeu atentados terroristas no reino da Jordânia (LISTER, 2014). Em 2003, o grupo de Zarqawi já se encontrava estabelecido no Iraque e, em agosto daquele ano, assumiu a autoria dos primeiros grandes atos de insurgência contra tropas da coalizão liderada pelos Estados Unidos (LISTER, 2014).

Em setembro de 2004 ocorre uma inflexão na cena jihadista iraquiana com a formação de uma aliança entre a JTWJ de Zarqawi e a Al-Qaeda de bin Laden (MAPPING MILITANT ORGANIZATIONS, 2015). A partir disso, o grupo passou a se denominar Al-Qaeda no Iraque (AQI), sendo considerado um afiliado da organização de bin Laden. Essa união se baseava na perseguição de um objetivo comum das duas organizações, ou seja, o estabelecimento de um califado universal. Zarqawi foi mortalmente ferido em junho de 2006.

No final de 2006, a Al-Qaeda no Iraque e outros grupos insurgentes a ela vinculados anunciaram um Estado Islâmico do Iraque. Lister (2004) comenta que essa alteração de nomenclatura fazia parte da estratégia de evolução do grupo para ser reconhecido como um ator capaz de responder pela governança de territórios. A Al-Qaeda no Iraque, que por algum tempo também passou a ser chamado Estado Islâmico do Iraque, conquistou diversas cidades e se tornou o principal grupo insurgente iraquiano. Foi, contudo, desmantelado a partir de 2007 com a mudança de estratégia do governo norte-americano em relação à guerra, cujas medidas mais visiveis foram o envio de mais brigadas ao Iraque (Surge) e a aliança com lideranças tribais locais contra a insurgência sunita (Sunni Awakening) (AL-JABOURI, 2010). Boa parte de suas principais lideranças foram presas ou mortas pelas forças norte-americanas e seus militantes restavam intimidados diante da ofensiva das forças de ocupação contra a violência sectária por eles estabelecida (PETRAEUS, 2007).

O grupo viria a ressurgir no Iraque a partir de 2012, após a retirada das tropas norte-americanas. Conforme indica Lister (2014), nesse momento ocorria um distanciamento entre a Al-Qaeda no Iraque e o núcleo dirigente da Al-Qaeda baseado no Paquistão. É fundamental, nesse ponto, a manifestação do emir da Al-Qaeda de que o ElIL não é um afiliado ou associado de sua organização terrorista, desvinculando-a completamente de suas ações violentas na região em que atua. Ayman al-Zawahiri, em um comunicado datado de fevereiro de 2014 , 
afirmou que o Estado Islâmico do Iraque do Levante "não é um ramo da Al-Qaeda, não está vinculada a ele e o grupo [Al-Qaeda] não é responsável por seus atos" (AL-AKHBAR, 2014, p. 1, tradução nossa). Al-Zawahiri também criticou a forma como ocorrem as operações do EIIL.

Um ano antes, no início de 2013, o grupo já havia sido rebatizado para Estado Islâmico do Iraque e do Levante, ocasião em que ocorreu um divórcio definitivo entre não apenas o núcleo da Al-Qaeda no Paquistão, mas também com o grupo terrorista Jabhat al-Nusra, com efetiva atuação na guerra civil da Síria e até hoje afiliado à Al-Qaeda (MAPPING MILITANT ORGANIZATIONS, 2015). No final de junho de 2014, por sua vez, o grupo anunciou a criação de um Estado Islâmico, havendo uma readequação do nome da organização com a supressão do "do Iraque e do Levante" para apenas Estado Islâmico³ (IS, em inglês) (PROMISE OF ALLAH, 2014).

Esse rápido panorama do EIIL mostra que essa organização se tornou algo distinto da Al-Qaeda e não manteve vínculos com os atentados terroristas de 11 de Setembro. Não seria, assim, uma herdeira do grupo de Osama bin Laden justamente porque agora ela compete com a Al-Qaeda e seus afiliados pelo domínio territorial do Oriente Médio. Parece pouco importar se Al-Qaeda e EIIL possuem uma agenda jihadista comum, pois no que tange à aplicabilidade da AUFM é o evento irradiador que importa, ou seja, o 11 de Setembro - a que o Estado Islâmico não está relacionado. Essas questões e outras mais que indicam com clareza que o ElIL não é uma organização subordinada ou ligada à Al-Qaeda, entretanto, não foram levadas em consideração pela administração Obama.

Nessa primeira fase do uso da força militar contra o EllL, portanto, transparece uma inadequação entre as ações do presidente e sua pretensa base legitimadora. A AUFM de 2001 parece não conferir legitimidade à atuação do presidente, sendo um argumento pouco robusto a sustentar o emprego do poder militar norte-americano contra o ElIL. Excluído esse recurso, resta apenas o poder do presidente como comandante-em-chefe e responsável pela segurança da nação. Trata-se de um argumento que se consolida na cena institucional dos Estados Unidos toda vez que um presidente, sem qualquer estatuto legislativo, mobiliza as forças militares do país - poder aéreo ou tropas terrestres - em conflitos no exterior.

O mais adequado, no caso do presidente, seria solicitar ao Congresso uma autorização específica para combater o ElIL, dar prosseguimento aos ataques aéreos e inclusive possibilitar o envio de tropas terrestres combatentes em maior número. Com o desenrolar dos acontecimentos na região, um avanço do EIIL no controle de territórios e cidades no Iraque e na Síria, o presidente finalmente solicitou ao Congresso uma autorização específica para combater o grupo terrorista no início de 2015. Com essa medida Obama pretendeu inaugurar uma segunda fase na utilização das forças armadas norte-americanas contra o ElIL.

\section{Fase II - A AUFM específica contra o EIIL}

Barack Obama enviou ao Congresso norte-americano em 11 de fevereiro de 2015 o rascunho de uma resolução para autorizá-lo a utilizar as forças militares para combater e destruir o Estado

3 Até hoje, no entanto, o grupo continua sendo também denominado de Estado Islâmico do Iraque e do Levante ou, ainda, do Iraque e da Síria. 
Islâmico. Esse pedido de Autorização para o Uso da Força Militar é o primeiro da administração do democrata.

Historicamente, mesmo que a autorização para a utilização da força militar seja uma atribuição do Legislativo nacional, é o Poder Executivo, na figura do presidente da República, quem provoca o Congresso a aprovar autorizações para a mobilização de militares (GRIMMETT, 2011). No caso de Obama, seguindo um padrão de presidentes anteriores, além do rascunho ele também remeteu aos congressistas uma carta introduzindo algumas questões importantes para que uma autorização, tal qual a requisitada, fosse fornecida pelas legislaturas nacionais.

O democrata inicia a missiva repetindo o argumento já utilizado em seu pronunciamento televisivo de 10 de setembro de 2014. Ao reafirmar seu posicionamento de meses antes, Obama escreve que "o chamado EIIL representa uma ameaça para a população e estabilidade do Iraque, Síria e Oriente Médio como um todo e para a segurança nacional dos Estados Unidos" (OBAMA, 2015, p. 1, tradução nossa). É sublinhado o aspecto ameaçador do ElIL para os cidadãos norteamericanos na região, bem como para a segurança das instalações do país existentes na área conflagrada. Diante desses fatos, seria necessária uma ação contra a organização, uma vez que "se não for combatido, o ElIL será uma ameaça para além do Oriente Médio, incluindo para o território dos Estados Unidos" (OBAMA, 2015, p. 1, tradução nossa).

Na carta Obama diz possuir uma "estratégia abrangente e sustentável para desintegrar e derrotar o EIIL" (OBAMA, 2015, p. 1, tradução nossa). Os ataques aéreos contra alvos do ISIS na Síria e no Iraque e empreendidos desde agosto do ano passado à revelia de uma autorização congressual formal são mencionados como parte dessa estratégia. Nesse ponto, e reafirmando sua crença anterior, Obama diz que agira desde então a partir de leis que o autorizariam a utilizar o poder aéreo. Ele fala, aqui, da própria Constituição interpretada de modo a fornecer ao presidente a prerrogativa de iniciar participação em conflitos e da AUFM de setembro de 2001.

A questão importante a se notar é que, embora já empoderado para defender os interesses da nação no exterior, segundo a versão de Obama ele sempre frisou a necessidade de trabalhar por uma resolução bipartidária no Congresso que estabelecesse um claro apoio dos parlamentares para que o presidente desse prosseguimento às ações militares contra o EIIL. É, então, dentro desse espírito que o presidente submetia o rascunho de uma AUFM contra o Estado Islâmico, devendo ele ser apreciado pelos congressistas para que fosse assegurada a continuidade das ações militares na Síria e no Iraque.

O envio de um pedido de autorização para utilização dos militares norte-americanos contra o ElIL demarca, pois, uma segunda fase no esforço para combater o grupo na região do Oriente Médio. É representativa dessa segunda fase uma relativa inflexão no discurso e nas possibilidades de atuação militar do país, uma vez que o envio de tropas terrestres tornou-se uma decisão.

Essa decisão de que tropas terrestres serão utilizadas, no entanto, não encontraria parâmetro nos conflitos mais recentes de que participaram os Estados Unidos. "O rascunho da AUFM da minha administração não autorizaria operações militares de combate terrestre de longo prazo e em larga escala como as que nossa nação conduziu no Iraque e Afeganistão", precaveu-se Obama (2015, p. 1, tradução nossa). Na visão do presidente as "forças locais" devem ser as responsáveis pelas grandes operações militares contra o ElIL. 
O que o presidente propõe é, como ele próprio ressalta, uma "flexibilidade para a condução de operações de combate terrestre" (OBAMA, 2015, p. 1, tradução nossa). Em termos práticos isso significa que as operações terão uma natureza limitada, tais como "operações de resgate envolvendo pessoal dos Estados Unidos ou da coalizão ou o uso de forças de operações especiais para tomar uma ação militar contra a liderança do EIIL" (OBAMA, 2015, p. 1, tradução nossa). A "flexibilidade" também inclui "o uso de forças norte-americanas em situações imprevistas de combate terrestre, como quando da coleta de dados para a inteligência" ou "a provisão de planejamento operacional e outras formas de aconselhamento e assistência às forças aliadas" (OBAMA, 2015, p. 1, tradução nossa).

O documento introduzido por Obama, em seu conteúdo, "não autoriza o uso das Forças Armadas dos Estados Unidos para suportar operações ofensivas de combate terrestre" (AUMFISIL, 2015, p. 2, tradução nossa). Trata-se de um recurso utilizado pela administração de Obama para expor à opinião pública doméstica a sua não intenção de despachar contingentes expressivos de militares norte-americanos para combater o EIIL e, assim, aproximar-se das guerras sem fim da Era Bush. Além disso, a ação militar contra o ElIL é percebida como defensiva e não ofensiva.

Nessa segunda fase de combate ao EIIL, a proposta de AUFM possui uma previsão de sua duração, devendo a autorização para a utilização da força militar expirar em três anos a contar da data de aprovação pelo Congresso. Outra possibilidade também prevista é a de que seja aprovada uma reautorização para as operações contra o grupo terrorista. Esse ponto é significativo, pois impõe ao Executivo um prazo final para encerrar as ações defensivas conta o EIIL.

A proposta de autorização enviada pelo Executivo tem como foco o uso das Forças Armadas contra o EIIL ou "pessoas ou forças associadas" a ele. Segundo o artigo quinto do texto, "pessoas ou forças associadas" são definidas como "indivíduos e organizações lutando pelo EIIL, em seu nome ou ao seu lado, ou qualquer entidade sucessora intimamente relacionada a hostilidades contra os Estados Unidos ou seus parceiros de coalizão" (AUMF-EIIL, 2015, p. 3, tradução nossa). A amplitude dessa definição é notável, possibilitando que diversos atores possam receber tratamento militar através dessa nova AUFM.

Pela nova AUFM proposta pelo governo Obama, portanto, as forças militares norteamericanas estariam autorizadas a neutralizar qualquer indivíduo ou organização que guarde algum tipo de relação com o ElIL e que estabeleça hostilidades contra não apenas os Estados Unidos, mas também países membros da coalizão formada para derrotar o EIIL. Qual a razão de ser de um pedido de autorização tão ampla solicitada pelo presidente democrata?

A razão principal é a de que o ElIL, como se sabe, não é um Estado na acepção moderna do termo. Não é, por exemplo, reconhecido por qualquer país atualmente, não possuindo qualquer legitimidade no atual sistema internacional. Um de seus objetivos, vale destacar, é o de erodir as atuais fronteiras estatais no interior do Oriente Médio e assimilar os Estados ao califado com jurisdição universal sobre os muçulmanos. Além disso, o ElIL não possui um exército regular cujas tropas são identificadas a partir de uniformes e cujos regulamentos preveem o respeito aos costumes e convenções do direito internacional. Muitos de seus combatentes, conforme reconheceu o próprio Obama, provêm de países europeus que, recebendo treinamento pelos 
radicais na Síria e no Iraque, tornam-se potenciais terroristas em seus países de origem. Tratase, em resumo, de uma ameaça irregular que não se concentra em um território determinado, senão espalhado em diversos pontos e para o qual as estratégias clássicas de conflitos militares regulares não possuem efetividade reconhecida. Essa amplitude da AUFM-EIIL, portanto, seria uma exigência da própria natureza do inimigo a ser combatido.

Um último ponto significativo da resolução proposta é que ela não revoga a AUFM de 2001. Mesmo, portanto, que uma Autorização específica para o ElIL fosse aprovada pelos congressistas, a presidência seguiria podendo utilizar a AUFM como fonte legitimadora para suas incursões no exterior. Note-se que Obama seguiria, assim, com duas amplas autorizações para combater o terrorismo internacional: a AUFM de 2001 e a AUFM-EIIL de 2015.

Esse rascunho, no entanto, ainda não foi, até o momento (final de outubro de 2015) apreciado pelo Congresso. Há formado um consenso de que o texto proposto pelo presidente é incapaz de formar maioria na Câmara dos Representantes e no Senado, sendo criticado tanto por congressistas democratas quanto por republicanos. Em geral, os primeiros alegam que a proposta de Obama poderia abrir caminho para a utilização de tropas em beligerâncias em solo, ao passo que líderes republicanos consideram muito limitadas as ações permitidas ao presidente.

Sem um consenso bipartidário mínimo, e com certo receio de desgaste dos congressistas em relação ao eleitorado, que poderia rememorar o uso de tropas nas impopulares guerras do Iraque e do Afeganistão, a inação impera. Alguns parlamentares, por sua vez, têm apresentado outras propostas de autorização alternativas à proposta inicial de Obama. A questão, no entanto, parece não evoluir na Comissão de Relações Exteriores do Senado.

Conforme escreveu Knox (2015), há dois consensos partidários nesse momento, a saber, o de que a AUFM de Obama não possui condições mínimas de ser aprovada e que a Casa Branca teria "lavado as mãos" em relação ao debate da autorização. Esse último ponto é importante, uma vez que historicamente tem sido o presidente aquele que articula a aprovação de autorizações para utilização dos militares no exterior.

No início de maio de 2015, um jornalista questionou em coletiva de imprensa o porta-voz Earnest sobre o que a administração estava fazendo para obter uma AUFM do Congresso. Ele então respondeu que achava que "fizemos praticamente tudo o que é imaginável que um Poder Executivo pode fazer para tentar fazer avançar uma lei através do Congresso" (EARNEST, 2015, p. 10, tradução nossa).

O porta-voz sublinha que o Congresso dos Estados Unidos, no momento em que era chamado para o debate, se comportou essencialmente como um "AWOL", expressão que na língua inglesa significa absent without leave, ou seja, como um soldado que deserta diante de seus compromissos. Earnest (2015, p. 10, tradução nossa), no entanto, afirma que esse comportamento do Legislativo "não tem impactado na capacidade do presidente, como Comandante-em-Chefe, ou quaisquer altos oficiais militares, de ordenar as operações que são necessárias para proteger a segurança nacional dos Estados Unidos".

Diante dessa situação, e sem um comprometimento dos congressistas para avançar na estratégia de destruição do ElIL, o presidente segue sem efetivar uma nova fase no esforço militar contra o inimigo no Oriente Médio. Ele, no entanto, continua a agir e mobiliza as 
forças armadas de forma limitada no exterior sem qualquer manifestação do Legislativo. Enquanto o Congresso permanece em silêncio Obama institucionaliza ainda mais a prática de envolver-se em conflitos no exterior sem uma expressa autorização dos representantes do povo norte-americano.

\section{Considerações finais}

Mesmo sem uma autorização congressual específica, as forças armadas norte-americanas estão sendo utilizadas para combater o ElIL na região do Oriente Médio desde o segundo semestre de 2014. Essa utilização tem se dado, basicamente, a partir do uso do poder aéreo em território sírio e iraquiano. Veículos aéreos não tripulados também têm sido empregados nos ataques contra o grupo insurgente. Além disso, o governo norte-americano despachou centenas de militares especializados para reforçar o treinamento das forças de segurança do Iraque.

Todas essas iniciativas promovidas pela administração de Barack Obama, conforme mostramos ao longo do artigo, são legitimadas em função do poder constitucional do presidente enquanto comandante-em-chefe da nação e, também, dos dispositivos da AUFM de 2001, documento que fundamentou a chamada "guerra ao terror" dos anos W. Bush.

Em relação ao primeiro argumento, o de que há previsão constitucional para o presidente mobilizar as forças armadas no exterior (e, no caso de Obama, o poder aéreo), ele tem sido historicamente utilizado, particularmente a partir da Guerra da Coreia (1950-1953), como sendo a fonte primária para que o presidente possa intervir militarmente no exterior sem qualquer autorização congressual. Os presidentes têm alegado que há, pois, um poder inerente ao chefe do Executivo norte-americano, a saber, o de proteger a nação se necessário a partir do emprego das forças de coerção a seu comando.

O outro argumento confere uma interpretação heterodoxa da AUFM de 2001. Aprovada pelo Congresso no contexto dos ataques terroristas de 11 de setembro, essa autorização destinava-se a empoderar o presidente para mobilizar as forças armadas no exterior contra nações, grupos e indivíduos envolvidos nos atos em Washington e Nova York. A administração de Obama tem interpretado a AUFM como passível de ser aplicada ao combate contra o EIIL, pois essa organização seria a sucessora do grupo Al-Qaeda no Iraque, uma afiliada do núcleo da Al-Qaeda (liderada por Osama bin Laden), autora do 11 de Setembro. Vimos, contudo, que é temerário considerar o Estado Islâmico como o herdeiro da Al-Qaeda, dentre outros motivos porque suas lideranças atuais em nada têm a ver com os atentados de 11 de setembro, além de existirem declarações públicas do emir da Al-Qaeda de afastamento do grupo terrorista que atua principalmente na Síria e no Iraque.

É, portanto, basicamente através desses argumentos que Barack Obama tem buscado legitimar o uso das forças armadas contra o EIIL desde agosto de 2014 na Síria e no Iraque. Em fevereiro de 2015, no entanto, o democrata buscou inaugurar uma segunda fase no esforço contra os extremistas, apresentando aos congressistas uma proposta de autorização para que as forças militares norte-americanas fossem mais ativas no confronto, inclusive com o envio de tropas terrestres. Esse pedido de uma AUFM específica para o ElIL acabou por revelar a 
insuficiência da AUFM de 2001. Poderíamos mesmo dizer que o presidente buscou "regularizar" suas ações.

O Legislativo nacional, contudo, até o momento não aprovou a AUFM-EIIL. Republicanos e democratas não concordam, por razões distintas, com os termos estabelecidos no rascunho enviado. Ao mesmo tempo, o Executivo parece não ter disposição para influir na tramitação da autorização. Diante disso, Obama permanece utilizando o poder aéreo contra o ElIL baseado em sua suposta autoridade constitucional para fazê-lo, além da utilização do instrumento normativo principal da "guerra ao terror" da Era Bush.

O Congresso não autoriza uma ação militar mais efetiva, tampouco censura o presidente por mobilizar o poder aéreo. Assim, convencido de que detém a soberania para intervir no exterior, o presidente segue utilizando as forças armadas contra o ElIL. É o Congresso o ramo político que tem condições de controlar o poder presidencial nestes casos. Ao não fazer esse controle, há um reforço do poder presidencial de Barack Obama.

Ao não mobilizar-se, portanto, o Congresso corre o risco de assistir a seus poderes de guerra ser usurpados pela suposta soberania presidencial para a guerra. Um sinal dessa realidade é que recentemente um grupo de operações especiais, em beligerância na Síria, eliminou um líder graduado do ElIL. Militares norte-americanos assim agiram sem qualquer autorização congressual, porém assentados por uma ordem do comandante-em-chefe da nação. O confronto das forças norte-americanas com o EIIL no Oriente Médio tende a se ampliar, com ou sem a anuência do Congresso. 0 embasamento jurídico e institucional permanece, no entanto, sendo precário, mesmo que utilizado pelo Executivo.

\section{Referências}

AL-AKHBAR. 2014. Al-Qaeda leader reiterates ISIS disavowal. Al-Akhbar, February 3. Disponível em: [http://english.al-akhbar.com/content/al-qaeda-leader-reiterates-isis-disavowal]. Acesso em: 04/ março/2015.

AL-JABOURI, Najim Abed; JENSEN, Sterling. 2010. The Iraqi and AQI roles in the Sunni Awakening. Prism, v. 2, p. 3-18.

AUMF. 2001. Authorization for Use of Military Force, Public Law 107-40. U.S. Congress Documents, Sept 18. Disponivel em: [http://www.gpo.gov/fdsys/pkg/PLAW-107publ40/pdf/PLAW-107publ40.pdf]. Acesso em: 18/abril/2015.

AUMF-ISIL. 2015. Joint Resolution - To authorize the limited use of the United States Armed Forces against the Islamic State of Iraq and the Levant. The White House, February 11. Disponivel em: [https:// www.whitehouse.gov/sites/default/files/docs/aumf_02112015.pdf]. Acesso em: 10/abril/2015.

BACKGROUND CONFERENCE. 2014. Background Conference Call on the President's Address to the Nation. The White House, Washington DC, Sept 10. Disponivel em: [https://www.whitehouse.gov/ the-press-office/2014/09/10/background-conference-call-presidents-address-nation]. Acesso em: 01/março/2015. 
BUSH, George W.. 2001. Address to a Joint Session of Congress and the American People. The White House, Sept 20. Disponivel em: [http://georgewbush-whitehouse.archives.gov/news/releases/2001/ 09/20010920-8.html]. Acesso em: 10/abril/2015.

WEED, Matthew. 2013. Memorandum: The 2001 Authorization for Use of Military Force. Congressional Research Service, July 10. Disponivel em: [https://lee.house.gov/sites/lee.house.gov/files/AUMF\%20 Brief\%20Background\%20Memorandum\%20(w\%20Appendix)_Released.pdf]. Acesso em: 10/dezembro/2014.

DAMIN, Cláudio Júnior. 2012. A guerra como instrumento do poder presidencial nos EUA: o caso da intervenção na Líbia. Boletim Meridiano 47, v. 13, n. 133, p. $19-25$.

DAMIN, Cláudio Júnior. 2013. Poder de Guerra nos Estados Unidos: a Cláusula da Guerra, o precedente coreano de 1950 e a autonomia do Comandante-em-Chefe. Tese de Doutorado. Universidade Federal do Rio Grande do Sul.

EARNEST, John. 2015. Press Briefing by Press Secretary Josh Earnest, 5/1/2015. The White House, Washington DC, May 02. Disponivel em: [https://www.whitehouse.gov/the-press-office/2015/05/02/ press-briefing-press-secretary-josh-earnest-512015]. Acesso em: 15/maio/2015.

EARNEST, John. 2014. Press Briefing by Press Secretary Josh Earnest. The White House, Washington DC, Sept 11. Disponivel em: [https://www.whitehouse.gov/the-press-office/2014/09/11/press-briefingpress-secretary-josh-earnest-9112014]. Acesso em: 15/abril/2015.

ELLIOT, Jonathan. 1836. The Debates in the Several State Conventions of the Adoption of the Federal Constitution, Vol. I (Mass., Conn., NH, NY, Penn, Maryland).

GRIMMETT, Richard; ELSEA, Jennifer. 2011 Declarations of War and Authorizations for the Use of Military Force: Historical Background and Legal Implications. Washington: Congressional Research Service.

HOFFMAN, Tod. 2014. Al Qaeda Declares War: The African Embassy Bombings and America's Search for Justice. ForeEdge.

ISIS VIDEO. 2014. Flames Of War - Latest ISLAMIC STATE Propaganda Video: "The Fighting Has Just Begun". Youtube, Sept 19. Disponivel em: [https://www.youtube.com/watch?v=wyOKe1SZjwk]. Acesso em: 20/abril/2015.

KERNELL, Samuel. 2006. Going public: New strategies of presidential leadership. CQ Press.

KNOX, Olivier. 2015. Nine months in, Congress mute on Obama's war against the Islamic State. Yahoo Politics, May 7. Disponivel em: [https://www.yahoo.com/politics/nine-months-in-congress-mute-onobamas-war-118384131406.html]. Acesso: 15/maio/2015.

LISTER, Charles. 2014. Profiling the Islamic State. Brookings Doha Center Analysis Center Number 13. November. Disponivel em: [http://www.brookings.edu/ /media/Research/Files/Reports/2014/11/ profiling\%20islamic\%20state\%20lister/en_web_lister.pdf]. Acesso em: 10/janeiro/2015.

MAPPING MILITANT ORGANIZATIONS. 2015. The Islamic State. Stanford University. Disponivel em: [http://web.stanford.edu/group/mappingmilitants/cgi-bin/groups/view/1\#note82]. Acesso em: 10/março/2015. 
OBAMA, Barack. 2015. Letter from the President - Authorization for the Use of United States Armed Forces in connection with the Islamic State of Iraq and the Levant. The White House, February 11. Disponivel em: [https://www.whitehouse.gov/the-press-office/2015/02/11/letter-presidentauthorization-use-united-states-armed-forces-connection]. Acesso em: 10/abril/2015.

OBAMA, Barack. 2014. Statement by the President on ISIL. The White House, Washington DC, Sept 10. Disponivel em: [https://www.whitehouse.gov/the-press-office/2014/09/10/statement-presidentISIL-1]. Acesso em: 05/março/2015.

PETRAEUS, David H. 2007. Report to Congress on the Situation in Iraq. Assistant Secretary of Defense (Public Affairs), Washington DC. Disponivel em: [http://www.dtic.mil/dtic/tr/fulltext/u2/a473579.pdf]. Acesso em: 20/janeiro/2015.

PROMISE OF ALLAH. 2014. ISIS Spokesman Declares Caliphate, Rebrands Group as "Islamic State". June 29. Disponivel em: [https://news.siteintelgroup.com/Jihadist-News/isis-spokesman-declarescaliphate-rebrands-group-as-islamic-state.html]. Acesso em: 20/janeiro/2015.

RAMSEY, Michael D.. 2003. Presidential Declarations of War. UC Davis L. Rev. , v. 37.

TRIBE, Laurence. 2004. The Constitution in Crisis: From Bush v. Gore to the War on Terrorism. The Tanner Lectures on Human Values.

TSANG, Derek. 2014. To justify ISIS airstrikes, Obama using legislation he wants repealed. Sept 18. Disponivel em: [http://www.politifact.com/punditfact/statements/2014/sep/18/julie-pace/justify-airstrikesagainst-islamic-state-obama-usi/]. Acesso em: 16/abril/2015.

Recebido em: 16 junho 2015 Aceito em: 23 setembro 2015 